J. Dairy Sci. 92:5951-5963

doi:10.3168/jds.2008-1979

(c) American Dairy Science Association, 2009.

\title{
Meta-analysis of stray voltage on dairy cattle
}

\author{
L. S. Erdreich, ${ }^{* 1}$ D. D. Alexander,† M. E. Wagner, ${ }^{*}$ and D. Reinemann \\ *Exponent Inc., 420 Lexington Avenue, Suite 1740, New York, NY 10170 \\ †Exponent Inc., 185 Hansen Court, Suite 100, Wood Dale, IL 60191 \\ fUniversity of Wisconsin Milking Research and Instruction Lab, Madison, WI 53706
}

\section{ABSTRACT}

A quantitative assessment of dairy cow responses to contact current (stray voltage) at 50 or $60 \mathrm{~Hz}$ was conducted using meta-analysis and pooled analysis methodology. The objective was to more accurately quantify the minimum exposure level (threshold) at which dairy cows respond and to identify sources of heterogeneity among studies. Several medical and agricultural databases were used to locate individual studies for the systematic literature review, from which 22 published studies of stray voltage and behavioral response or milk yield met our inclusion criteria. Meta-analysis models were constructed to assess the percentage of cows with a behavioral response at documented exposure levels, and the summary relative risk estimate for all exposure pathways combined was calculated for each 1-mA increment from 1.0 through $5.0 \mathrm{~mA}$. The meta-analysis of percentage response showed that cows exhibited statistically significant first behavioral responses at $3.0 \mathrm{~mA}$, response probability increased with exposure levels, and exposure pathways contributed to heterogeneity in the model. The pooled analysis of mean behavioral response threshold was based on experimental studies of ascending series of current exposures on 355 cows. The overall weighted mean for first behavioral response to current was $4.0 \mathrm{~mA}$. Ten of the studies that met the inclusion criteria addressed milk production, but heterogeneity in exposure pathways, patterns, and duration precluded meta-analysis or data pooling. The milk production studies ranged in size from 4 to 48 cows and used switchback or paired design to increase power. A qualitative narrative review of these studies indicated that production was not affected by exposure to contact current at levels of $3 \mathrm{~mA}$ or lower for exposures of up to $21 \mathrm{~d}$ or 4 wk.

Key words: dairy cow, stray voltage, meta-analysis, contact current

\footnotetext{
Received December 16, 2008.

Accepted August 21, 2009.

${ }^{1}$ Corresponding author: lerdreich@exponent.com
}

\section{INTRODUCTION}

Numerous studies have been conducted to identify the lowest intensity of contact currents, also referred to as stray voltage, that causes dairy cows to respond in various ways. These studies used a variety of methods and analytical designs to identify a response threshold; that is, the lowest level of contact current that can be reliably associated with a specified physiological change or observable behavioral response. A response threshold has been used as the basis for regulatory policy established to limit exposures of dairy cows to stray voltage (PSCW, 1996). Some of the studies in this area of research are based on relatively small sample sizes and, therefore, have high variability in their summary and outcome measures.

The most common threshold of response for dairy cows used in the scientific literature has been a change in behavioral response to a short-term exposure (from seconds to hours) to contact currents (USDA, 1991; Reinemann et al., 2005). Neurological theory and practice indicates that as current exposures increase in magnitude, sensory nerves are the first to respond (resulting in sensations), followed by motor nerves (resulting in involuntary muscle contraction) at higher levels of current exposure (Reilly, 1998). Stimulation of sensory nerves can result in a "startle" response that tends to decrease with repeated exposure, whereas stimulation of motor nerves results in involuntary muscle contraction or a "twitch" response that presumably does not decrease with repeated exposure as it is involuntary.

In this report, meta-analysis and pooled analysis methods were used to summarize data across scientific studies to accurately and precisely estimate the association between stray voltage exposure levels and dairy cow responses. Meta-analysis is a statistical technique for combining and summarizing results data from independent studies. Its effectiveness in science and medicine lies in its objectivity and transparency of methods, compared with traditional narrative reviews, and its ability to explore the factors that contribute to differences among the relevant studies. Moreover, by nature 
of its design, a meta-analysis allows for the evaluation of an association or effect with greater statistical power (i.e., the ability to detect a difference if one truly exists) and more precise results [i.e., a narrower confidence interval (CI)]. Essential components of a meta-analysis include the quantitative and qualitative assessment of potential sources of heterogeneity (e.g., variability due to study design, experimental method) across studies, the identification of factors that may contribute to this variability, and the identification of high-impact studies that may influence the overall study results (Blair et al., 1995; Greenland, 1998; Sutton et al., 1999). A pooled analysis is a type of meta-analysis that combines individual-level data (i.e., raw data) from related studies producing a new "pooled" result. The advantage of a pooled analysis is that having data on individual subjects allows the researcher to aggregate data into common categories, rather than having to rely on the data summaries reported in published manuscripts or reports. Meta- and pooled analyses are supported by a systematic review, which is the process used to identify the data that are appropriate for inclusion; it is the systematic review that gives meta-analysis its objectivity and transparency.

A systematic review of the literature was conducted to identify original, peer-reviewed experimental studies on cows of 50 or $60 \mathrm{~Hz}$ alternating current (AC) or voltage that reported data on either behavioral response thresholds or milk yield. Scientifically accepted procedures were followed for the conduct and reporting of the meta-analysis (Blair et al., 1995; Greenland, 1998). This literature set is unique in that various experimental schema have been used by the individual studies (e.g., exposure pathway, frequency of exposure, definition of response), with strong commonalities typically limited to studies conducted by the same group of researchers. These differences may preclude the combination of studies or necessitate the use of a least common denominator of some variables, such as exposure assessment. Thus, like any meta-analysis, a secondary purpose of this report is to evaluate these sources of heterogeneity to determine whether a meta-analysis is feasible.

The objectives of this systematic literature review and quantitative assessment were to 1) identify studies that evaluated the effects of stray voltage on dairy cattle, 2) use meta-analysis and pooled analysis methodology to calculate a more precise estimate of short-term behavioral response thresholds, and 3) evaluate the likelihood that long-term exposure to contact currents affects milk yield or other physiological responses.

\section{MATERIALS AND METHODS}

\section{Systematic Literature Review}

The goal of this systematic literature review was to identify original, experimental studies involving controlled exposure to alternating (sinusoidal) currents or voltages at 50 or $60 \mathrm{~Hz}$ and short-term behavioral-perception responses, changes in production (milk or rate of gain), or other physiological responses (e.g., immune changes, endocrine changes).

No single database is suitable for a systematic literature review of this topic; therefore, multiple databases and methods were used to identify studies of relevance. Search terms were developed that included a term that referenced the phenomenon of stray voltage (e.g., "contact voltage" or "transient voltage" or "aversive voltage" or "steady state voltage" or "contact current" or "transient current" or "neutral-to-earth voltage") and a term that referenced possible animals of interest (cows). These terms were used to search PubMed through June 2007 (190 hits) and the American Society of Agricultural and Biological Engineers (ASAE/ ASABE) database through June 2007 (13 hits), which includes articles from 3 relevant journals from 1998 to the present. (PubMed is a search engine provided by the National Library of Medicine and the National Institutes of Health that includes over 15 million upto-date citations from MEDLINE and other life science journals for biomedical articles dating back to the 1950s; http://www.pubmed.gov.)

When the analysis was completed, we repeated the search on the main databases, PubMed, and ASABE through November 2008. No additional studies meeting the criteria were identified.

Twenty-two publications from these databases met our initial selection criteria. A reference librarian was employed to search additional agricultural and veterinary resources for the same period (Agricola, Agris, NTIS, GPO Mon. Cat., Energy SciTec, CAB Abstracts, Biological and Agricultural Index, Zoological Record Online, Ei Compendex INSPEC, Mechanical and Transport Engineer Abstract, Pascal, ToxFile, Elsevier Biobase, Embase, CSA Life Sciences Abstracts) using the same search terms. This search produced over 500 hits, and an additional 107 references of possible relevance were identified. Two scientists independently screened these unique articles (approximately 129) following criteria that were developed a priori.

To verify that our literature set was complete, the reference lists from original articles were hand-searched. In addition, the literature set was matched against the 
personal library of one of the researchers (D. R.). The following additional studies were identified using these 2 methods: 3 English-language, peer-reviewed original publications on cows; 1 non-English language study; 18 reviews; 12 reports of studies without exposure data on individual animals (ecological studies); and 15 Englishlanguage, non-peer-reviewed publications on cows.

\section{Study Inclusion/Exclusion Criteria}

Each article was screened for the following inclusion/ exclusion criteria: studies published in peer-reviewed literature that evaluated controlled alternating (sinusoidal) current or voltage exposure at 50 or $60 \mathrm{~Hz}$ and short-term behavioral-perception responses, changes in production (milk or rate of gain), or other physiological responses (e.g., immune-endocrine changes, heart rate) were included. In addition, for the purposes of this assessment, and to reduce heterogeneity, only studies of cows were included. Review articles, case reports, news articles, or other lay-oriented material related to stray voltage and reported health effects were excluded, as were descriptive studies of stray voltage measurements or the effects of exposure to electric and magnetic fields. Ecological studies, which correlated global stray voltage measures with herd-level data, were also excluded.

A total of 22 studies were identified that met the above inclusion criteria. The following studies were excluded for the cited reason: 12 non-English language documents that did not meet the entire set of inclusion criteria; 34 review articles; 7 news articles or other layoriented materials; 7 ecological studies; 7 case reports; 11 descriptive studies of stray voltage measurements; 1 study on electric and magnetic fields; 9 studies of pigs; and about 20 studies that were not peer-reviewed, including conference proceedings and dissertations.

\section{Data Extraction}

The studies were organized by outcome (percentage of cows with short-term behavioral response at specified exposure levels, response threshold, and milk yield) and exposure pathway (front hooves-rear hooves, teats-hooves, muzzle-all hooves, lumbar/body exposure application, and water bowl exposure application). The following information was extracted independently by 2 reviewers for studies of short-term behavioral response and for milk yield data:

- Characteristics of experimental and control groups and selection criteria

- Type of exposure (current or voltage), frequency, and waveform (50 or $60 \mathrm{~Hz}$, sine wave)
- Experimental design, including the frequency and duration of exposure and any reported methods used for the assignment of exposure, application of exposure, recording of response variables, and replication

- Results data or individual-level data, including sample size, exposure level and any information on the variability of the response or statistical significance of comparisons between exposure levels

- Any relevant comments regarding study design or results

\section{Statistical Analysis}

Studies that reported the percentage of cows that showed a behavioral response at each exposure level or included sufficient data to allow calculation of the percentage behavioral response among the exposed and the unexposed were included in the meta-analysis. Percentage response is an estimate of the probability of the response, or risk. The measure of the behavioral response at a given exposure is the ratio of the percentage response (risk) in the exposed to the percentage response in the unexposed; this rate ratio is known as the relative risk. A relative risk of 1.0 indicates no effect of exposure, because it means that the response was the same in the 2 groups that were compared. In the metaanalysis, the term "summary relative risk" refers to the weighted average of all relative risk estimates obtained from individual studies, with larger studies providing a greater influence on the weighted summary.

Quantitative assessments of dairy cow behavioral responses to current exposure were conducted utilizing meta-analysis and pooled analysis methodology. Specifically, the summary relative risk among studies that reported data for percentage behavioral response was estimated and the weighted mean behavioral response threshold for ascending series current exposures across studies that reported these data was generated. Relative risk is the ratio of the probability (risk) of the outcome among the exposed to the probability of the outcome among the unexposed (control group). It is also known as the risk ratio. The relative risk is typically estimated by data from individual studies. Summary relative risk refers to the estimate from meta-analysis, in which the data from individual studies are pooled or weighted. In addition, data were pooled across studies to estimate the distribution of behavioral response threshold levels among various outcome classifications. The incorporation of 2 quantitative methodologies (i.e., meta- and pooled) allowed for a more robust evaluation of the data.

Several meta-analysis models were constructed that allowed the examination of potential patterns of as- 
sociations comprehensively across a variety of exposure and outcome metrics. For the assessment of percentage behavioral response, 2 studies (Norell et al., 1983; Gustafson et al., 1985) were identified for distinct pathways in which relevant data could be extracted and meta-analyzed. The exposure pathways among these studies included "front to rear hooves," "mouth to all hooves," and "body to all hooves." In the individual studies, data were reported as the percentage of cows with a behavioral response for each level of exposure in milliamperes. Thus, the data were standardized across studies in the form of relative risks for each incremental milliampere exposure category, using the lowest category (i.e., $0 \mathrm{~mA}$ ) as the referent group. In the meta-analysis model, the summary relative risk estimate (SRRE) for all exposure pathways combined was calculated for each 1.0-mA incremental level of exposure through 5.0 mA (Greenland, 1998; Borenstein, 2007). Sensitivity meta-analysis models were constructed for each exposure pathway; however, these models were statistically underpowered because of limited data.

In the threshold evaluation, in which an ascending series of $60 \mathrm{~Hz}$ current was applied through various body pathways until a behavioral response threshold was observed, data on 355 dairy cows were pooled across studies (Woolford, 1972; Whittlestone, 1975; Lefcourt, 1982; Norell et al., 1983; Gorewit et al., 1984; Lefcourt et al., 1986; Currence et al., 1990; Reinemann, 1996; Aneshansley et al., 1997; Reinemann et al., 1999, 2003; Aneshansley and Gorewit, 1999). Because some of these studies were not published in peer-reviewed journals, sensitivity analysis were conducted to assess the effect on results of removing unpublished data. In these studies, a predefined behavioral response was monitored in individual cows during the course of a series of tests in which the current dose was gradually increased until such a response was elicited. Across all studies, the response levels were converted into equivalent 60 $\mathrm{Hz}$ root mean square (rms) steady-state levels using relationships from measurement practice (e.g., $1.0 \mathrm{~mA}$ measured from zero-to-peak for a sinusoidal waveform $=0.707 \mathrm{~mA} \mathrm{rms}$ ) and from neuro-electric models with experimental verification (e.g., the response to a single cycle sinusoidal stimulus is equivalent to about $80 \%$ of the same waveform applied in a continuous or multiple cycle manner). The outcomes that were evaluated in the threshold assessment were behavioral response, discomfort, and aversion.

For the meta-analysis assessment of behavioral response threshold levels, the mean value, standard deviation, and sample size were calculated and recorded for each individual study. These values were included in pooled analysis models for each outcome classification (i.e., first behavioral response, discomfort, aversion).
Thus, weighted mean threshold levels and corresponding $95 \%$ confidence intervals (CI) were calculated, based on the relative weight, or influence, of each study in a particular model.

Random effects models were used to calculate SRRE, 95\% CI, and corresponding $P$-values for heterogeneity. The random effects model assumes that the studyspecific effect sizes come from a random distribution of effect sizes according to a specific mean and variance (Sutton et al., 1999). The estimates of the individual studies were weighted based on the inverse of the variance, which is related to the sizes of the study populations. In the sensitivity analyses, the relative influence of each study on the model-specific SRRE was examined by generating an SRRE based on all studies in a particular model, followed by the removal of one study at a time to compare the overall SRRE with SRRE from models that had one study removed. This allowed for the determination of the statistical robustness of each analytical model.

Publication bias can affect meta-analysis findings if results from individual studies have been published differentially (e.g., positive studies are more likely to be published than negative studies). Publication bias was assessed by generating funnel plots for a visual examination, conducting correlation and regression tests for significance, and using a "trim and fill" procedure to evaluate symmetry around the summary effect (Rothstein et al., 2005). All analyses were performed using Comprehensive Meta-Analysis software (Borenstein, 2007) and Episheet (Andersson and Ahlbom, 2004), a spreadsheet-based analytical package designed for the analysis of epidemiologic data. The use of 2 independent analytical programs allowed for the validation of calculations.

\section{RESULTS}

Table 1 lists the study characteristics of the 22 peerreviewed, English-language studies of stray voltage effects on cows. This table indicates whether the published data were previously published in a non-peerreviewed format and whether stray voltage effects on behavioral outcomes, production variables, and other outcomes were assessed. Although 16 studies reported data on behavioral outcomes, 5 presented general conclusions only without supporting data. To be used in the summary meta-analysis for percentage behavioral response, studies had to provide data used for calculating a risk estimate; many lacked data on the number of cows in each category. In addition, exposure pathways, response measures, and categories of exposure levels differed among studies. Only 2 studies provided data that were sufficiently similar and suitable for the sum- 
mary meta-analysis (Figures 1 and 2). The sample sizes of these studies were 5 and 7 per exposure level.

Data for a pooled analysis on mean threshold were abstracted from published studies, obtained from the researcher, or from unpublished version of papers eventually published (e.g., conference presentations or technical papers). The pooled analysis combined results of studies on dairy cows in which an ascending series of $60 \mathrm{~Hz}$ current was applied through various body pathways until a behavioral response threshold was observed. These data represent 355 cows, in 15 separate experiments, by 9 research groups (Woolford, 1972; Whittlestone, 1975; Lefcourt, 1982; Norell et al., 1983; Gorewit et al., 1984; Lefcourt et al., 1986; Currence et al., 1990; Reinemann, 1996; Aneshansley et al., 1997; Aneshansley and Gorewit, 1999; Reinemann et al., 1999, 2003).

In the meta-analyses of percentage behavioral response by exposure level, no positive associations $(P$ $<0.05)$ were evident at $1.0 \mathrm{~mA}(\mathrm{SRRE}=1.22,95 \%$ CI: $0.75-1.98)$ or $2.0 \mathrm{~mA}$ (SRRE $=1.50,95 \%$ CI: 0.90-2.49) compared with dairy cows that received no current exposure. The $95 \%$ CI did not exclude 1.0 until a current exposure of $3.0 \mathrm{~mA}(\mathrm{SRRE}=2.98,95 \% \mathrm{CI}$ : 1.76-5.05), $4.0 \mathrm{~mA}$ (SRRE $=3.97,95 \%$ CI: $2.02-7.81$ ), and $5.0 \mathrm{~mA}$ (SRRE $=6.64,95 \%$ CI: $3.18-13.88)$ (Figures 1 and 2). An exposure-response trend was apparent as the relative risk increased monotonically with each incremental level of exposure. (Monotonic refers to a mathematical function that means consistently increasing and never decreasing, or consistently decreasing and never increasing. We refer to monotonic as the situation for which there is an increase in risk with every increasing category or level of exposure.) Heterogeneity was indicated (i.e., $P$-value for heterogeneity $<0.05)$ in all models except the $1.0 \mathrm{~mA}$ model. The observed heterogeneity was explained primarily by the "mouth to all hooves" exposure pathway data from Norell et al. (1983). Results for this exposure pathway were considerably stronger in magnitude compared with data from the other studies. In our sub-group analyses, summary associations (based on data from 2 studies) for the "mouth to all hooves" pathway were at least 5 times stronger in magnitude for the $2.0 \mathrm{~mA}$ through the $5.0 \mathrm{~mA}$ exposure analyses compared with the "front to rear hooves" and "body to all hooves" results (data not shown).

Figure 3 illustrates the behavioral response thresholds, based on the pooled analysis, among dairy cows exposed to ascending series currents. Approximately $80 \%$ (i.e., 10 to $90 \%$ cumulative distribution) of all first behavioral responses were elicited between 3.0 and $8.0 \mathrm{~mA}$ of $60 \mathrm{~Hz} \mathrm{rms}$ current. The 50th percentile of responses was just below $5.0 \mathrm{~mA}$. The threshold of involuntary muscle contraction would be expected to occur at higher current dose levels than the threshold of sensory stimulation. When discomfort, considered to be a more repeatable (stronger or more pronounced behavioral) response, was analyzed as the outcome of interest, the threshold shifted modestly in the positive direction. That is, approximately $80 \%$ of the responses ranged between 4.0 and $10.0 \mathrm{~mA}$ with the 50 th percentile falling at $6.5 \mathrm{~mA}$. Fewer studies reported data for aversive response thresholds (e.g., stop drinking) and thresholds at which cows appeared to be in pain. As expected, among these studies, $80 \%$ of the cows exhibited an aversive response between higher values (i.e., 5.5 to $16.0 \mathrm{~mA}$ ), and the 50th percentile for aversion was just below $9.0 \mathrm{~mA}$.

The meta-analyses of behavioral response thresholds support the observations based on the pooled data cumulative distributions. The weighted mean average threshold level in which a first behavioral response was elicited among dairy cows was $3.99 \mathrm{~mA}$ (95\% CI: 3.22-4.76), and significant variability was observed across these studies $(P$-value for heterogeneity $<0.001$; Figure 4). Variability in this meta-analysis model was likely caused by heterogeneity in exposure pathways and outcome classifications across studies. Comprehensive subgroup analyses to explore potential sources of heterogeneity could not be performed because data were sparse after stratifying by exposure pathway and outcome. Consistent with the results of the pooled data, in which the 50th percentile for discomfort was approximately $6.5 \mathrm{~mA}$, the weighted mean average for discomfort response in the meta-analysis was $6.2 \mathrm{~mA}$ (95\% CI: $5.28-7.13 ; P$-value for heterogeneity $<0.001$; Figure 5). In the meta-analysis of an aversive response threshold, the weighted mean level was 9.71 (95\% CI: 6.93-12.49; $P$-value for heterogeneity $<0.001$; data not shown).

Sensitivity analysis was conducted to determine whether results were affected by inclusion of non-peerreviewed data in the pooled meta-analysis. The metaanalysis of behavioral response threshold (Figures 4 and 5) was repeated excluding data from non-peer-reviewed sources. Results from these analyses, however, did not markedly alter the overall summary associations. Indeed, the weighted mean changed from 3.99 to 3.76 in the first behavioral response analysis, but the summary effect became less precise (i.e., 95\% CI: 2.64-4.88), after removing the data from non-peer-reviewed sources (Woolford, 1972; Reinemann, 1996; Aneshansley et al., 1997; Aneshansley and Gorewit, 1999; Reinemann and Thompson, 2003). In the sensitivity analysis of discomfort response, removing data from Aneshansley et al. 
Table 1. Study characteristics of the outcomes assessed in the 22 peer-reviewed, English-language studies of stray voltage effects on cows identified from the systematic literature or review, including searches of PubMed and American Society of Agricultural and Biological Engineers (ASABE) databases

\begin{tabular}{|c|c|c|}
\hline Citation & Behavioral outcomes assessed? & Production assessed? \\
\hline Aneshansley et al., 1992 & Yes; general conclusions (no supporting data) & $\begin{array}{l}\text { Yes; milking yield, residual milk, milking duration, } \\
\text { milk fat and protein and somatic cell counts }\end{array}$ \\
\hline Currence et al., 1990 & $\begin{array}{l}\text { Yes; visible clues of cows sensing electrical } \\
\text { current (lifting a hoof, humping back, } \\
\text { muscle contraction) }\end{array}$ & No \\
\hline Gorewit et al., 1985 & Yes; general conclusions (no supporting data) & $\begin{array}{l}\text { Yes; milking yield, milk fat and protein } \\
\text { and somatic cell counts }\end{array}$ \\
\hline Gorewit and Scott, 1986 & No & Yes; general conclusions (no supporting data) \\
\hline Gorewit et al., 1989 & No & Yes; milking yield, milk fat and protein \\
\hline Gorewit et al., 1992a & No & $\begin{array}{l}\text { Yes; milking yield, milk fat and protein } \\
\text { and somatic cell counts }\end{array}$ \\
\hline Gorewit et al., 1992b & No & No \\
\hline
\end{tabular}

Gustafson et al., 1985 Gumprich, 1992 Yes; raise front hoof and open mouth
No

Henke-Drenkard et al., 1985

Lefcourt and Akers, 1982

Lefcourt, 1982

Lefcourt et al., 1985

Lefcourt et al., 1986

Norell et al., 1983

Reinemann et al., 1995

Reinemann et al., 1999a

Reinemann et al., 2002

Reinemann et al., 2003 Reinemann et al., 2004

Reinemann et al., 2005

Whittlestone, 1975
Yes

No

Yes; mild and distinct responses

Yes; general conclusions (no supporting data)

Yes; general conclusions (no supporting data)

Yes; clear positive response based on

observations of cow behavior (leg lifting,

facial reaction or tail switches)

Yes; clear positive response based on

observations of cow behavior (leg lifting,

facial reaction or tail switches)

Yes; activity (weight shifts)

Yes; startle response

Yes; behavioral response

Yes; clear positive response based on

observations of cow behavior (leg lifting,

facial reaction or tail switches)
No

Yes; milking yield, milking duration, milk fat, protein and lactose and somatic cell counts

Yes; milking yield, residual milk, milking duration, peak milk flow rate, milk fat

and protein and somatic cell counts

Yes; milk yield and duration

No

Yes; milk yield and duration, maximum flow

rate and time to maximum flow rate

Yes, although data are only provided in the form of graphs with no ability to extract data

No

ther outcomes assessed?

Cortisol

No

Water intake and feed consumption

Mammary gland blood flow rate;

heart rate; blood pressure

Water intake and feed consumption

Water intake and feed consumption

Mastitis, hoof problems, changes in body weight, days to first breeding, services per conception, response to $\mathrm{PGF}$, calving intervals, visible abortion, and calves born dead

Water intake, feed consumption, breeding, and behavior (urinating, defecating, and drinking times) Cortisol, prolactin, and oxytocin

Dopamine, prolactin, oxytocin, norepinephrine and epinephrine No

Heart rate, mastitis, oxytocin and prolactin

Heart rate, prolactin, glucocorticoids, norepinephrine and epinephrine No

No

No

Yes; milk yield, average flow rate, maximum flow rate, strip yield and liner slips No

No

Yes; milk yield 
(1997), Aneshansley and Gorewit (1999), Reinemann and Thompson (2003), and Woolford (1972) reduced the weighted mean modestly (i.e., from 6.20 to 5.41).

The studies reporting data on milk yield were evaluated qualitatively and it was determined that heterogeneity in the type of outcome reported for similar exposure levels and pathways precluded a meta-analysis of these effects. We conducted a narrative review of the studies of contact current that assessed quantitative data on milk yield and milking time at levels that produce modest behavioral changes. Nine published studies and one government report were found that reported information on current exposure and milk yield (Lefcourt and Akers, 1982; Gorewit et al., 1985, 1989, 1992a; Henke-Drenkard et al., 1985; Lefcourt et al., 1985; Aneshansley et al., 1992; Gumprich, 1992; Reinemann et al., 2002, 2005). Two other studies stated that exposure to current had no effect on milk yield but were excluded because they did not provide quantitative data (Gorewit and Scott, 1986; Lefcourt et al., 1986). The only study that assessed health and production over a complete lactation found no evidence of adverse effects on measures of the animals' health, or reduced average daily yield, actual 305-d total or mature-equivalent yield in exposed animals compared with those with 1,2 , or $4 \mathrm{~V}$ on the waterer (Gorewit et al., 1992a,b). The study used 10 different animals in each of the study groups and had limited power to detect changes in milk yield at lower levels of interest to the farmer. Other studies have incorporated statis-

\section{Study (Exposure Pathway)}

Exposure Level

\begin{tabular}{|c|c|}
\hline Gustafson 1985 (F to R) & $1.0 \mathrm{~mA}$ \\
\hline Norell 1983 ( $F$ to $R$ ) & $1.0 \mathrm{~mA}$ \\
\hline Gustafson 1985 (M to A) & $1.0 \mathrm{~mA}$ \\
\hline Norell 1983 (M to A) & $1.0 \mathrm{~mA}$ \\
\hline \multicolumn{2}{|c|}{ Summary Relative Risk = $1.22(0.75-1.98)$} \\
\hline Gustafson 1985 ( $F$ to R) & $2.0 \mathrm{~mA}$ \\
\hline Norell 1983 ( $F$ to R) & $2.0 \mathrm{~mA}$ \\
\hline Gustafson 1985 (M to A) & $2.0 \mathrm{~mA}$ \\
\hline Norell 1983 (M to A) & $2.0 \mathrm{~mA}$ \\
\hline $\begin{array}{l}\text { Gustafson } 1985 \text { (B to A) } \\
\text { Summary Rela }\end{array}$ & Summary Relative Risk = $1.50(0.90-2.4 \biguplus$ \\
\hline Gustafson 1985 ( $F$ to $R$ ) & $3.0 \mathrm{~mA}$ \\
\hline Norell 1983 ( $F$ to R) & $3.0 \mathrm{~mA}$ \\
\hline Gustafson 1985 (M to A) & $3.0 \mathrm{~mA}$ \\
\hline Norell 1983 (M to A) & $3.0 \mathrm{~mA}$ \\
\hline Summary Relative Risk = $2.98(1.76-5.0$ & $\begin{array}{l}3.0 \mathrm{~mA} \\
.76-5.05\end{array}$ \\
\hline Gustafson 1985 ( $F$ to $R$ ) & $4.0 \mathrm{~mA}$ \\
\hline Norell $1983(\mathrm{~F}$ to $\mathrm{R})$ & $4.0 \mathrm{~mA}$ \\
\hline Gustafson 1985 (M to A) & $4.0 \mathrm{~mA}$ \\
\hline Norell $1983(M$ to A) & $4.0 \mathrm{~mA}$ \\
\hline \multicolumn{2}{|c|}{ Summary Relative Risk $=3.97(2.02-7.8$} \\
\hline Gustafson 1985 ( $F$ to $R$ ) & $5.0 \mathrm{~mA}$ \\
\hline Norell 1983 ( $F$ to R) & $5.0 \mathrm{~mA}$ \\
\hline Gustafson 1985 (M to A) & $5.0 \mathrm{~mA}$ \\
\hline Norell 1983 ( $M$ to A) & $5.0 \mathrm{~mA}$ \\
\hline
\end{tabular}

Summary Relative Risk $=6.64$ (3.18-13.88)

\section{$\mathrm{RR}$ and $95 \% \mathrm{Cl}$}

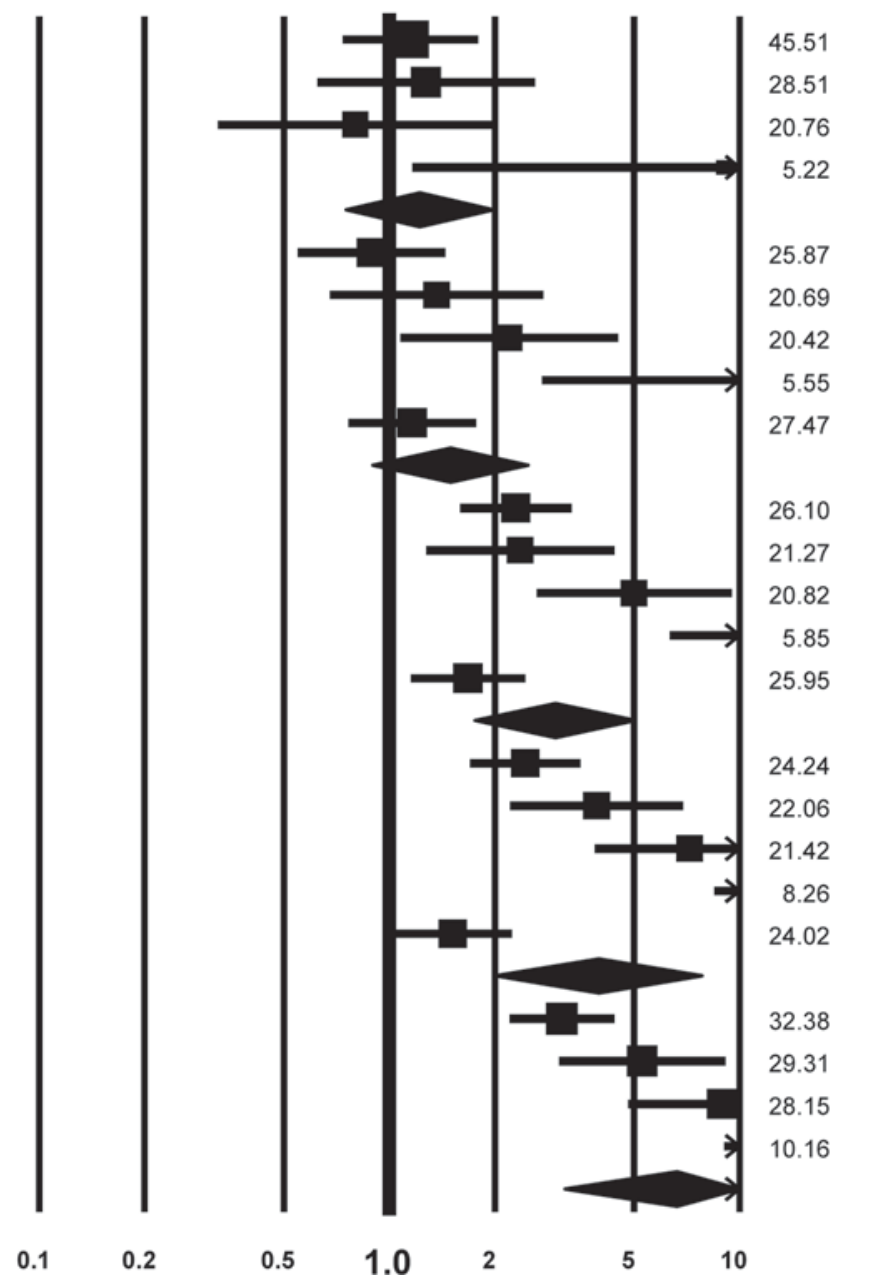

Figure 1. Summary relative risk (RR) from meta-analysis and 95\% confidence intervals (CI) ( $\bullet$ ) across studies of dairy cows, from individual studies that reported data for percentage of behavioral response by pathway and exposure level (ם). (Individual point estimates represented by boxes, summary associations [meta-analysis] represented by diamonds). Studies are identified by first author and year. $\mathrm{F}=$ front hooves; $\mathrm{R}=$ rear hooves; $\mathrm{M}=$ muzzle; $\mathrm{A}=$ all hooves. 
Exposure Level

\section{RR Lower Upper \\ limit limit}

$1.0 \mathrm{~mA}$

1.22

0.75

1.98

$2.0 \mathrm{~mA}$

1.50

0.90

2.49

$3.0 \mathrm{~mA}$

2.98

1.76

5.05

4.0 mA

3.97

2.02

7.81

$5.0 \mathrm{~mA}$
6.64

\section{$3.18 \quad 13.88$}

RR and $95 \%$ CI

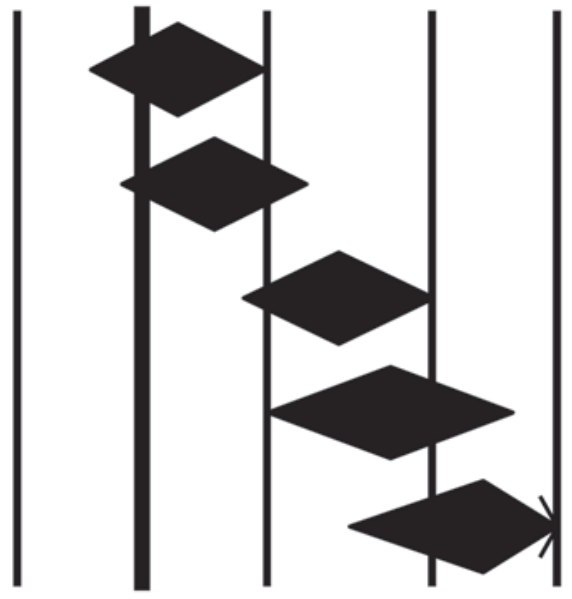

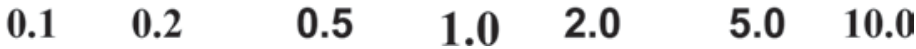

Figure 2. Summary relative risk (RR) from meta-analysis and $95 \%$ confidence intervals (CI) representing the relative risks of the behavioral response percent by exposure level across studies of dairy cows.

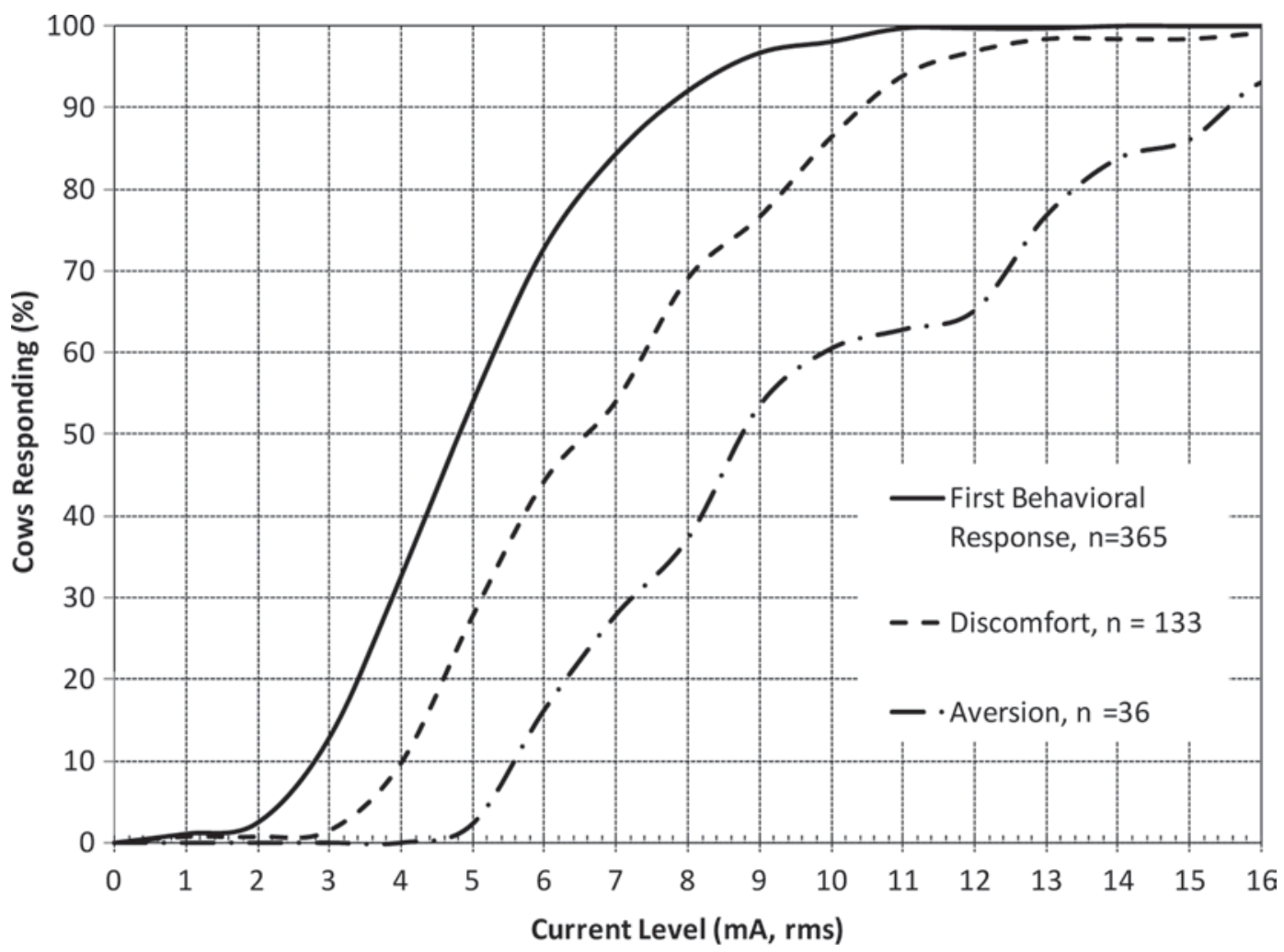

Figure 3. Pooled cumulative incidence of behavioral response thresholds for first response, discomfort, and aversion among dairy cows exposed to ascending series of sinusoidal $60 \mathrm{~Hz}$ currents. 


\section{Study name}

Aneshansley 97/99
Currence 1990
Gorewit 84/85
Lefcourt 1982
Lefcourt 1986
Norell 1983
Reineman 1999
Reineman 1996
Reineman 2003
Whittlestone 1975
Woolford 1972
Weighted Mean

\section{Mean Limit Limit}

$\begin{array}{lll}3.79 & 3.40 & 4.18 \\ 3.80 & 3.35 & 4.25 \\ 3.00 & 1.87 & 4.13 \\ 2.48 & 1.49 & 3.47 \\ 3.93 & 2.94 & 4.92 \\ 1.70 & 0.74 & 2.66 \\ 5.59 & 5.25 & 5.93 \\ 5.47 & 5.19 & 5.75 \\ 3.00 & 2.63 & 3.37 \\ 5.61 & 4.64 & 6.58 \\ 5.36 & 4.06 & 6.65 \\ \mathbf{3 . 9 9} & \mathbf{3 . 2 2} & \mathbf{4 . 7 6}\end{array}$

\section{Mean and $95 \%$ CI}

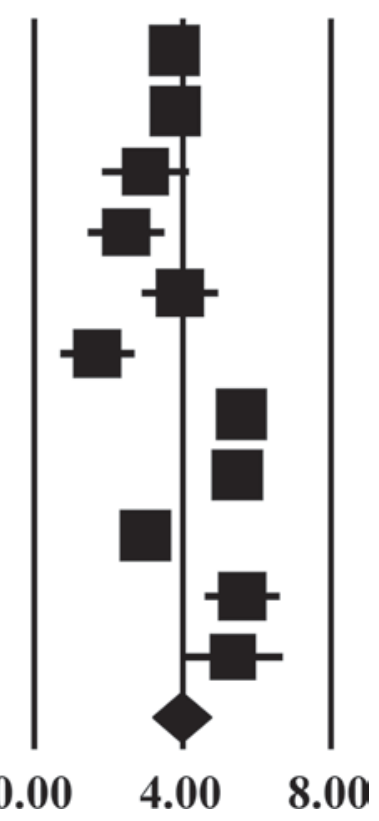

Figure 4. Summary relative risk from meta-analysis and 95\% confidence intervals (CI) ( $\bullet$ representing the weighted average of the behavioral response threshold among dairy cows exposed to stray voltage compared with estimates from individual studies ( $\boldsymbol{\square}$ ). Studies are identified by first author and year.

tical methods to increase power by reducing variability among the subjects, typically by using switchback designs or each cow as its own control (paired data); these are summarized in Table 2. As Table 2 shows, exposure varied by pathway, patterns, and duration. This heterogeneity precluded our efforts to pool the data or conduct a meta-analysis of results. Pathways included udder, skin, or nose or mouth (water bowl) to all hooves, continuous or intermittent exposures, and duration ranging from $1 \mathrm{~d}$ to $4 \mathrm{wk}$. Overall, these studies have reported that production was not affected by treatment at levels as low as $1.5 \mathrm{~mA}$ for exposures of up to $21 \mathrm{~d}$ or $4 \mathrm{wk}$.

Our assessment of publication bias revealed some outliers in several of the funnel plots for the respective meta-analysis models; however, statistical tests did not indicate publication bias. It should be noted, however, that evaluations of potential publication bias might not be particularly effective when evaluating a relatively small sample of studies, such as in this meta-analysis.

\section{DISCUSSION}

Meta-analysis techniques allow researchers to summarize data across individual studies, which may have small sample sizes, to better discern potential patterns of associations among study-specific factors of sub- groups. To the best of our knowledge, this is the first meta-analysis of data on contact current relevant to stray voltage. The results of this quantitative assessment indicate that at sufficient levels, exposure of dairy cows to electric currents may lead to behavioral responses of the nervous system. These data show a clear pattern of increased probability of response (Figure 2 ) and increased severity of behavioral response with increasing dose levels (dose-response effect, Figures 4 and 5). These results provide evidence of a threshold at approximately $3.0 \mathrm{~mA}$, whereas no statistically significant behavioral responses were observed below this level among dairy cows.

The major concern of dairy farmers is herd health and production, and preventing behavioral outcomes such as aversion would be a means toward that end. Some have speculated that long-term exposure to contact currents at levels below behavioral thresholds damage the endocrine or immune systems of dairy cattle, thus affecting the health and productivity of the herd. This is not supported, however, by published scientific research. Individual studies to date have not reported long-term effects of internal currents on production, immune or endocrine systems, or other health parameters (Gorewit et al., 1992a,b; Reinemann et al., 2002). Unfortunately, the data available on milk production 
Study name

Aneshansley 1997
Aneshansley 1999
Gorewit 1984/85
Lefcourt 1982
Lefcourt 1986
Norell 1983
Reinemann 1999
Reinemann 2003
Woolford 1972
Weighted Mean

Lower Upper Mean Limit Limit

$\begin{array}{rrr}4.58 & 3.95 & 5.20 \\ 9.30 & 7.52 & 11.08 \\ 6.00 & 6.00 & 6.00 \\ 3.50 & 2.16 & 4.84 \\ 7.86 & 6.19 & 9.52 \\ 3.60 & 3.12 & 4.08 \\ 6.40 & 5.73 & 7.07 \\ 7.52 & 6.95 & 8.10 \\ 9.00 & 6.92 & 11.08 \\ \mathbf{6 . 2 0} & \mathbf{5 . 2 8} & \mathbf{7 . 1 3}\end{array}$

Mean and $95 \%$ CI

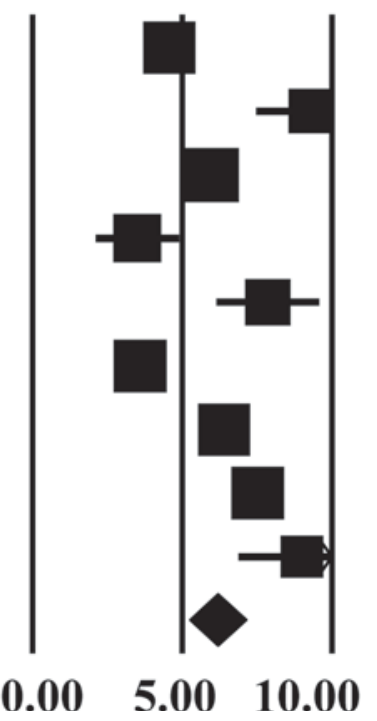

Figure 5. Summary relative risk from meta-analysis and $95 \%$ confidence intervals (CI) $(\bullet)$ representing the weighted average of the discomfort response threshold among dairy cows exposure to stray voltage compared with estimate from individual studies (ם). Studies are identified by first author and year.

could not be combined statistically in a meta-analysis because of heterogeneity in experimental protocols.

Several studies reported qualitative information noting that animals exposed to 8.0 or $12.0 \mathrm{~mA}$, or $4 \mathrm{~V}$ on the waterer, may take a few days to drink or become unmanageable at higher levels (Aneshansley et al., 1992; Gorewit et al., 1992a). The observed range of sensitivity in cows is not unexpected and is consistent with the biological meaning of threshold as an estimate of the minimum average response level in a population. Sensitivity has been addressed in a study that identified the threshold for individual animals and exposed at levels additive or multiples of the threshold (Reinemann et al., 2005).

Studies that did not have data on individual animals (ecological studies) were excluded because we modeled our approach to that used in human biomedical research. Clinical and epidemiologic studies that correlate exposures assessed on the level of the group, rather than the individual, are considered to be prone to error because an association observed between variables on an aggregate level (e.g., air pollution in a geographic area) does not necessarily represent that which would exist on the individual level (Last, 2001). For this reason, human ecological studies are not deemed suitable for assessing a direct cause-and-effect interpretation. In dairy cattle, however, the unit of interest in disease prevention is not the individual animal, but the herd (LeBlanc et al., 2006). A dairy herd on a farm is likely to be more homogeneous than diverse people in a geographic area and is less prone to aggregation bias than a human population. For this reason, the large field data collected by the Public Service Commission of Wisconsin should be noted as relevant because it focused on individual herds, using a uniform protocol across dairy herds, and correlated data on production on dairy farms with measured levels of contact current (PSCW, 2006). A scatter graph of more than 4,000 herds shows no evidence that increasing contact current measured on the farm results in decreased milk production (PSCW, 2006). These data are the largest field study to date and support the inferences from the extensive behavioral studies that contact currents at levels at or somewhat above the threshold for behavioral effects are unlikely to reduce milk production. This inference is supported as well by the more limited studies on milk yield, and the biological nature of neurological system responses.

Similarly, in every study that included both behavioral and endocrine responses as outcome variables, endocrine responses always occurred at levels exceeding the behavioral response threshold documented in this meta-analysis (Henke-Drenkard et al., 1985; USDA, 1991). These data also support inferences from behavioral studies that contact currents at or somewhat above the behavioral response threshold are unlikely to cause endocrine responses and subsequent compromise of immune function in dairy cows. 
Table 2. Summary of data and exposure characteristics of published studies of exposure to current and milk yield identified from the systematic literature review including searches of PubMed and American Society of Agricultural and Biological Engineers (ASABE) databases

\begin{tabular}{|c|c|c|c|c|c|c|}
\hline Reference & Number of cows & Exposure level & Pathway & Exposure pattern & Exposure duration & Results \\
\hline Aneshansley et al., 1992 & $\begin{array}{l}7 \text { first lactation; } \\
8 \text { multiple } \\
\text { lactation cows }\end{array}$ & $5 \mathrm{~mA}, 8 \mathrm{~mA}, 16 \mathrm{~mA}$ & $\begin{array}{r}\text { Udder (milking } \\
\text { machine liner) } \\
\text { to rear hooves }\end{array}$ & During milk flow & 6 consecutive milkings & $\begin{array}{l}\text { No difference in primary milk } \\
\text { yield }(P<0.05) \text { for first lactation } \\
\text { or multiple lactation cows }\end{array}$ \\
\hline Lefcourt et al., 1985 & $13(7$ and 6$)$ & $3.6 \mathrm{~mA}, 6 \mathrm{~mA}$ & $\begin{array}{l}\text { Right front and } \\
\text { rear hooves } \\
\text { to ground }\end{array}$ & $\begin{array}{l}\text { Current on } 5 \mathrm{~s} \\
\text { of every } 30 \mathrm{~s} \\
\text { (intermittent) }\end{array}$ & $\begin{array}{l}7 \mathrm{~d} \text {, } \mathrm{AM} \text { and } \mathrm{PM} \\
\text { milking }\end{array}$ & $\begin{array}{l}\text { No treatment related decrease. Milk } \\
\text { yield not affected by treatment per } \\
\text { least squares estimates, } P \text { not specified }\end{array}$ \\
\hline $\begin{array}{l}\text { Henke-Drenkard } \\
\text { et al., } 1985\end{array}$ & 6 per group & $0,4.8 \mathrm{~mA}$ & $\begin{array}{l}\text { Udder (teats) } \\
\text { to hooves }\end{array}$ & $\begin{array}{l}\text { Current on } 5 \mathrm{~s} \\
\text { of every } 30 \mathrm{~s} \\
\text { (intermittent) }\end{array}$ & $\begin{array}{l}\text { Before and during } \\
\text { milking } 7 \mathrm{~d} \text { exposure, } \\
\text { milk yield over } 4 \mathrm{~d}\end{array}$ & $\begin{array}{l}\text { No difference in mean daily yield } \\
\text { (at } P<0.05)\end{array}$ \\
\hline Gorewit et al., 1989 & $\begin{array}{l}15 \text { first parity } \\
\text { and } 15 \\
\text { multiparous } \\
\text { cows each group }\end{array}$ & $\begin{array}{l}0,0.5,1.0 \\
2.0,4.0 \mathrm{~V}^{1}\end{array}$ & $\begin{array}{l}\text { Mouth to all } \\
\text { hooves (water } \\
\text { bowls) }\end{array}$ & $\begin{array}{l}\text { Preexposure and } \\
\text { postexposure period } \\
\text { averaged as control }\end{array}$ & $21 \mathrm{~d}$ & $\begin{array}{l}\text { For all animals, mean daily yield } \\
\text { not different between control } \\
\text { and treatment periods }(P>0.25)\end{array}$ \\
\hline Gorewit et al., 1985 & 4 per group & $0 \mathrm{~mA}, 4 \mathrm{~mA}$ & Subdermal & Semirandom pattern & 4 consecutive days & Means not different at $P<0.05$ \\
\hline Lefcourt et al., 1985 & $\begin{array}{l}6 \text { Holstein cows } \\
\text { (5 for } \\
\text { intermittent })\end{array}$ & $5 \mathrm{~mA}$ & $\begin{array}{l}\text { Electrodes } \\
\text { attached to } \\
\text { shaved skin, } \\
\text { path not clear }\end{array}$ & $\begin{array}{l}\text { Continuous; } \\
\text { intermittent }\end{array}$ & $\begin{array}{l}\text { One milking. } \\
\text { Continuous for } 5 \text { min, } \\
\text { starting } 10 \text { min before } \\
\text { milking. Intermittently } \\
\text { for } 5 \text { of every } 30 \mathrm{~s}\end{array}$ & $\begin{array}{l}\text { Continuous exposure, no decrease } \\
\text { in yield, } P \text { not specified. Intermittent } \\
\text { voltage, decrease (at } P<0.1)\end{array}$ \\
\hline Reinemann et al., 2002 & 48 cows & $1 \mathrm{~mA}$ & $\begin{array}{l}\text { Front to rear } \\
\text { hooves }\end{array}$ & During milking & $\begin{array}{l}1 \text { treatment day. } \\
\text { Compared with } \\
\text { average yield } \\
\text { of day before } \\
\text { and after treatment }\end{array}$ & $\begin{array}{l}\text { No difference in milk yield due } \\
\text { to current exposure, } P=0.84\end{array}$ \\
\hline Reinemann et al., 2005 & $\begin{array}{l}32 \text { cows, blocked } \\
\text { into } 8 \text { groups } \\
\text { of } 4 \text { cows }\end{array}$ & $\begin{array}{l}\text { Peak transient } \\
\text { current. Additive } \\
(1,5 \mathrm{~mA} ; 3 \mathrm{~mA}) \text { or } \\
\text { multiples }(1.5 \\
\text { times) of individual } \\
\text { cow's response } \\
\text { threshold }\end{array}$ & $\begin{array}{l}\text { Nose to all } \\
\text { hooves (water } \\
\text { bowls) }\end{array}$ & $\begin{array}{l}\text { Transient applied } \\
\text { once every } \\
\text { second, } 24 \mathrm{~h} / \mathrm{d}\end{array}$ & $\begin{array}{l}21 \text { consecutive days } \\
\text { treatment period. } \\
14 \mathrm{~d} \text { pre- and } \\
\text { post-treatment periods }\end{array}$ & $\begin{array}{l}\text { No treatment effect on milk yield } \\
\text { for additive exposure }(P=0.18) \text { or } \\
\text { multiplicative exposure groups } \\
(P=0.68)\end{array}$ \\
\hline Gumprich, 1992 & $\begin{array}{l}6 \text { groups of } 5 \\
\text { cows each }\end{array}$ & $\begin{array}{l}1.0,2.4,5 \mathrm{~V} \text { with } \\
\text { background of } \\
0.3,0.75 \text { and } 0.75\end{array}$ & $\begin{array}{l}\text { Voltage on } \\
\text { water bowl }\end{array}$ & $\begin{array}{l}\text { Voltage applied } \\
0500 \text { to } 0800 \mathrm{~h} \\
\text { and } 1700 \text { to } 2000 \mathrm{~h}\end{array}$ & $\begin{array}{l}4 \text { sequential periods } \\
\text { of exposure } 4 \text { wk each }\end{array}$ & $\begin{array}{l}\text { Average daily milk production not } \\
\text { decreased at } 1 \mathrm{~V}(P=0.1) \\
2.5 \mathrm{~V}(P=0.5) \text { or } 5 \mathrm{~V}(P=0.1)\end{array}$ \\
\hline
\end{tabular}


Although a systematic and comprehensive qualitative and quantitative assessment of the literature was conducted, interpretation may be limited by variation in exposure pathways, response measures, and categories of exposure levels across studies. In addition, there were sparse data across several subgroups, thereby limiting the ability to combine data in a meta-analysis format and precluding an inclusive examination of potential sources of heterogeneity. Despite these possible limitations, associations from the meta-analysis evaluations were relatively similar to the results from the pooled assessment, indicating coherence in the exposure-response relation.

\section{CONCLUSIONS}

Two types of quantitative methods were used in this analysis, meta-analysis of summary data and pooled analysis of data on each animal. The meta-analysis shows a clear behavioral response at $3.0 \mathrm{~mA}$ but not at lower levels. The results in the pooled analysis indicates that responses of most cows fall between 3.0 and $8.0 \mathrm{~mA}$ of $60 \mathrm{~Hz}$ current, with the 50th percentile just below 5.0 $\mathrm{mA}$. The consistency of these results supports the hypothesis that the behavioral response of cows to current is threshold acting, with responses unlikely below 3.0 $\mathrm{mA}$. These data also exhibit several other characteristics typically considered important to support validity of scientific inferences: replication, consistency, and biological plausibility. The study-specific data (Figures 1 and 4) indicate that results have been replicated by research teams within specific laboratories (universities) and by other researchers in different facilities. Results show a consistent threshold effect pattern, despite some differences in study designs, exposure pathways, and outcome classifications. The sequence of responses (from perception to discomfort to aversion) to exposure to increasing intensities of current and the existence of a threshold are as expected based on what is known about the nervous system's response to stimuli (e.g., Reilly, 1998). Behavioral responses are of concern to producers for their potential effect on production. Our systematic review of studies on milk production did not find data suitable for a meta-analysis or pooled analysis. However, the analysis of the experimental studies of milk yield and the large field study from the Public Service Commission of Wisconsin (PSCW, 2006) are consistent with the inference from the narrative review of studies of milk production that contact currents at $3.0 \mathrm{~mA}$ or even higher do not affect milk yields.

\section{REFERENCES}

Andersson, T., and A. Ahlbom. 2004. Episheet software: Spreadsheets for the analysis of epidemiologic data. Version Sep. 19, 2007.
Aneshansley, D. J., and R. C. Gorewit. 1999. Sensitivity of Holsteins to $60 \mathrm{~Hz}$ and other waveforms present on dairy farms. American Society of Agricultural Engineers Annual International Meeting. Technical Paper No. 99-3152:13. ASAE, St. Joseph, MI.

Aneshansley, D. J., R. C. Gorewit, and L. R. Price. 1992. Cow sensitivity to electricity during milking. J. Dairy Sci. 75:2733-2741.

Aneshansley, D. J., L. H. Southwick, R. A. Pellerin, R. C. Gorewit, and J. A. Throop. 1997. Aversive response of dairy cows to voltages/ currents on waterers at frequencies of $60 \mathrm{~Hz}$ and above. American Society of Agricultural Engineers Annual International Meeting Technical Paper. Paper No. 97-3109:8. ASAE, St. Joseph, MI.

Blair, A., J. Burg, J. Foran, H. Gibb, S. Greenland, R. Morris, G. Raabe, D. Savitz, J. Teta, D. Wartenberg, O. Wong, and R. Zimmerman. 1995. Guidelines for application of meta-analysis in environmental epidemiology. Regul. Toxicol. Pharmacol. 22:189-197.

Borenstein, M. 2007. Comprehensive Meta-Analysis. Biostat Inc. http://www.meta-analysis.com.

Currence, H. D., B. J. Steevens, D. F. Winter, W. K. Dick, and G. F. Krause. 1990. Dairy cow and human sensitivity to short duration, 60-Hertz currents. Appl. Eng. Agric. 6:349-353.

Gorewit, R. C., N. R. Scott, and D. V. Henke-Drenkard. 1984. Effects of electrical current on milk production and animal health. American Society of Agricultural Engineers Annual International Meeting Technical Paper No. 84:3502-3520. ASAE, St. Joseph, MI.

Gorewit, R. C., N. R. Scott, and C. S. Czarniecki. 1985. Responses of dairy cows to alternating electrical current administered semirandomly in a nonavoidance environment. J. Dairy Sci. 68:718-725.

Gorewit, R. C., and N. R. Scott. 1986. Cardiovascular responses of cows given electrical current during milking. J. Dairy Sci. 69:1122-1127.

Gorewit, R. C., D. J. Aneshansley, D. C. Ludington, R. A. Pellerin, and X. Zhao. 1989. AC voltages on water bowls: Effects on lactating Holsteins. J. Dairy Sci. 72:2184-2192.

Gorewit, R. C., D. J. Aneshansley, and L. R. Price. 1992a. Effects of voltages on cows over a complete lactation. 1. Milk yield and composition. J. Dairy Sci. 75:2719-2725.

Gorewit, R. C., D. J. Aneshansley, and L. R. Price. 1992b. Effects of voltages on cows over a complete lactation. 2. Health and reproduction. J. Dairy Sci. 75:2726-2732.

Greenland, S. 1998. Meta-Analysis. Pages 643-673 in Modern Epidemiology. 2nd ed. Lippincott Williams \& Wilkins, Philadelphia, PA.

Gumprich, P. 1992. Stray voltage effects on dairy cattle. August Report. New Liskeard College, Toronto, Ontario, Canada.

Gustafson, R. J., T. M. Brennan, and R. D. Appleman. 1985. Behavioral studies of dairy cow sensitivity to AC and to DC electric currents. Trans. ASAE 28:1680-1685.

Henke-Drenkard, D. V., R. C. Gorewit, N. R. Scott, and R. Sagi. 1985. Milk production, health, behavior, and endocrine responses of cows exposed to electrical current during milking. J. Dairy Sci. 68:2694-2702.

Last, J. M. 2001. A Dictionary of Epidemiology. 4th ed. Oxford University Press, London, UK.

LeBlanc, S. J., K. D. Lissemore, D. F. Kelton, T. F. Duffield, and K. E. Leslie. 2006. Major advances in disease prevention in dairy cattle. J. Dairy Sci. 89:1267-1279.

Lefcourt, A. 1982. Behavioral responses of dairy cows subjected to controlled voltages. J. Dairy Sci. 65:672-674.

Lefcourt, A. M., and R. M. Akers. 1982. Endocrine responses of cows subjected to controlled voltages during milking. J. Dairy Sci. 65:2125-2130.

Lefcourt, A. M., R. M. Akers, R. H. Miller, and B. Weinland. 1985. Effects of intermittent electrical shock responses related to milk ejection. J. Dairy Sci. 68:391-401.

Lefcourt, A. M., S. Kahl, and R. M. Akers. 1986. Correlation of indices of stress with intensity of electrical shock for cows. J. Dairy Sci. 69:833-842.

Norell, R. J., R. J. Gustafson, R. D. Appleman, and J. B. Overmier. 1983. Behavioral studies of dairy cattle sensitivity of electrical currents. Trans. ASAE 26:1506-1511. 
PSCW (Public Service Commission of Wisconsin). 1996. Findings of fact, conclusion of law, and order. Investigation on the commission's own motion into the practices, policies and procedures concerning stray voltage for electric distribution utilities in Wisconsin. 05-EI115. Public Service Commission of Wisconsin, Madison.

PSCW (Public Service Commission of Wisconsin). 2006. Stray voltage phase I and phase II combined database summary. Public Service Commission of Wisconsin, Madison.

Reilly, J. P. 1998. Sensory responses to electrical stimulation. Pages 240-298 in Applied Bioelectricity: From Electrical Stimulation to Electro-Pathology. Springer, New York, NY.

Reinemann, D. J. 1996. Dairy cow sensitivity and aversion to short duration transient currents. American Society of Agricultural Engineers Annual International Meeting. Technical Paper No.963087. ASAE, St. Joseph, MI.

Reinemann, D. J., M. D. Rasmussen, and S. D. LeMire. 2002. Milking performance of dairy cows subjected to electrical current and induced milking machine problems. Trans. ASAE 45:833-838.

Reinemann, D. J., L. E. Stetson, N. E. Laughlin, and S. D. LeMire. 2005. Water, feed, and milk production response of dairy cattle exposed to transient currents. Trans. ASAE 48:385-392.

Reinemann, D. J., L. E. Stetson, J. P. Reilly, and N. K. Laughlin. 1999. Dairy cow sensitivity to short duration electrical currents. Trans. ASAE 42:215-222.
Reinemann, D. J., and P. D. Thompson. 2003. Sensitivity Testing Results: EPRI PEAC Sponsored Pulsed Current Impact Assessment Tests, University of Wisconsin-Madison.

Reinemann, D. J., M. C. Wiltbank, M. D. Rasmussen, L. G. Sheffield, and S. D. LeMire. 2003. Comparison of behavioral to physiological response of cows exposed to electric shock. Trans. ASAE 46:507512.

Rothstein, H., A. Sutton, and M. Borenstein. 2005. Publication Bias in Meta-Analysis: Prevention, Assessments, and Adjustments. Springer, Amsterdam, the Netherlands.

Sutton, A. J., D. R. Jones, K. R. Abrams, T. A. Sheldon, and F. Song. 1999. Systematic reviews and meta analysis: A structured review of the methodological literature. J. Health Serv. Res. Policy 4:4955.

USDA. 1991. Effects of electrical voltage/current on farm animals: How to detect and remedy problems. A. M. Lefcourt, ed. Agriculture Handbook No. 696. USDA, Washington, DC.

Whittlestone, W. G. 1975. Electric shocks during machine milking. N. Z. Vet. J. 23:105-108.

Woolford, W. M. 1972. Small voltage in milking plants. Proceedings of the 2nd Seminar on Farm Machinery and Equipment. New Zealand Department of Agriculture, Wellington, New Zealand. 